dilution method and by its sensitivity to penicillinase.

At this point most researchers would have regarded the project as concluded. Not du Vigneaud. With his associates, he isolated penicillin $\mathrm{G}$ from the synthetic mixture through a series of purification steps, including the countercurrent distribution method developed about this time by Lyman C. Craig at the Rockefeller Institute, next door to Cornell. A crystalline salt of penicillin $G$ was obtained and shown to be identical with natural penicillin by an array of methods of physical chemistry, X-ray crystallography and biological activity. This unrelenting and uncompromising search for conclusive evidence was a characteristic feature of the research of du Vigneaud. The same standards were maintained when his interest turned to the peptide hormones, oxytocin and vasopressin.

The hormonal effects of extracts from the posterior lobe of the pituitary gland have been known since the turn of the century. In the late nineteentwenties, $O$. Kamm demonstrated the presence of two separate principles in the extracts, one oxytocic (quickening childbirth) and the other pressor and antidiuretic. A comment of Kamm on the relatively small molecular weight of the two hormonally active factors, oxytocin and vasopressin, sparked the interest of du Vigneaud. Although the penicillin studies interrupted his first attempts toward the isolation of the two peptide hormones $\mathrm{m}$ pure form, this effort was revived after the Second World War and led, in relatively short time, to the isolation of the pure peptides. Countercurrent distribution again played a major role in the success. Elucidation of the structures soon followed and in 1953 the endeavour was crowned by the synthesis of oxytocin, and later by the syntheses of lysine vasopressin and arginine vasopressin. These were epoch-making achievements. The 1955 Nobel Prize in Chemistry was awarded to Professor du Vigneaud "for his work on biochemically important sulphur-containing compounds, especially for the first synthesis of a polypeptide hormone.' Other awards, medals, honorary degrees received by him are too numerous to be mentioned here.

Many of us thought that having finished with oxytocin, Professor du Vigneaud would turn towards even more ambitious objectives, perhaps the synthesis of insulin. On such questions his answer was: 'Finished? We have just started.' And, indeed, the effort in the field of pituitary hormones was continued for almost twenty more years. Many of the results from his laboratory were trend-setting, such as a new synthesis of oxytocin by the stepwise strategy, an approach which was applied also to the synthesis of lysine vasopressin, and of numerous analogues of the two peptides. The availability of synthetic analogues permitted the exploration of the interaction between hormone and receptor. Functional groups were replaced by hydrogen, first the phenolic hydroxyl in oxytocin, then its single free amino group. Biologically active peptides were obtained. These studies gave new insight into hormonal activity and demonstrated the significance of architecture in peptides and proteins. In fact, Professor du Vigneaud liked to call oxytocin a "baby protein.' The body of information generated in this tireless effort is impressive: it appeared in about 200 publications, almost half of the total 'output' of du Vigneaud's published work.

The published reports, however, are certainly not the total of the du Vigneaud legacy. The daily contact with this exceptional man had a major influence on those of us who were fortunate enough to have spent some of our formative years in his laboratory. His account of declining a suggestion to accept responsibility for the synthesis of corticotropin, which at that time seemed to be more important than oxytocin, taught us to stick to commitments already made. By insisting on treating synthetic oxytocin with bromine-water to observe its cleavage into two fragments, as happens with natural oxytocin, he demonstrated the need for skepticism towards one's own results, at a time when nobody else had doubts about their correctness.

On his prompting, I had prepared a crystalline salt of synthetic oxytocin suitable for X-ray studies. A letter to Nature on the crystals was already typed when he came to my laboratory with a sample of natural oxytocin and requested that I repeat the crystallisation with natural oxytocin as well. Years after receiving the Nobel Prize, he still wanted to be sure that there was no difference between natural and synthetic preparations of the hormone. Scientific integrity was one of the lessons we could learn from him. Yet, his style, his flair for the important and his unshakeable optimism that the next major discovery is just around the corner were unique aspects of the man, which would be difficult to imitate.

Professor du Vigneaud is survived by his two children, Vincent du Vigneaud, Jr., an obstetrician and gynaecologist, and Marilyn Renee Brown, Assistant Professor of Pediatrics at the University of Rochester Medical Center. Those who were saddened by his departure also include his former associates, the 166 members of the 'V. du V. Club,' among them many distinguished scientists, including two Nobel laureates. Miklos Bodanszky

\section{Robert van den Bosch}

RoBert VAN DEN BosCh, Professor of Entomology and Chairman of the Division of Biological Control at the University of California, Berkeley, died while jogging on 19 November 1978. His death deprived the ranks of entomologists, ecologists, biological control specialists and environmentalists, world-wide, of an outstanding individual.

Van, as he was called by most who knew him, was born in Martinez, California on 31 March 1922. He received his BA in Physical Education from the University of California at Berkeley in 1943. From 1943 to 1946 he served as Deck Officer with the Amphibious Forces, US Naval Reserve, and saw heavy combat action in the Pacific. In 1947 he returned to the University of California, Berkeley as a student in entomology, receiving his $\mathrm{PhD}$ in that field in 1950.

In his professional career, besides being a researcher, a teacher, and an administrator in the Division of Biological Control and the Department of Entomological Sciences at the University of California, Berkeley, Van served as a member of the Board of Directors of the Rachel Carson Trust and a consultant to various national and international groups and institutions concerned with agricultural and environmental issues related to pest control. He was a fellow of the American Association for the Advancement of Sciences, and a Guggenheim Fellow.

The circuitous academic route followed by Professor van den Bosch was not as unusual as it might seem. In a communication written just before his death he clarified this by saying that bugs were his first love and that as a member of the Boy Scouts he was one of the rare ones who earned a merit badge in entomology. This was the major he chose when he came to the University of California as an undergraduate student in 1939. However, his interest and activities in athletics conflicted with the heavy laboratory schedule of an entomology major and so he shifted to the physical education major and there earned his AB degree. Following his service in World War II, however, he returned to his first and enduring loves: the University of California and Entomology. His keen intéllect, strong motivation and perseverance led Professors Ray F. Smith and E. Gorton Linsley to encourage him to work directly for his PhD, which he did under the direction of Professor Smith. As a fledgling PhD he became a member of the University of Hawaii faculty from 1949 to 1951 when he joined the University of California at 
Riverside, transferring to the Berkeley campus in 1963.

Professor van den Bosch was a leading researcher and spokesman for the discipline of biological control. The practice of biological control, based primarily on taxonomy, population ecology and insect behaviour, encompasses even wider areas and includes evolution and zoogeography as well as agriculture, forestry and public health. Robert van den Bosch was knowledgeable in all these areas and solidly grounded in several of them. Often accompanied by his wife, Peggy, he searched indefatigably for natural enemies of insect pests on the continents of Europe, Africa and Asia, winning the lasting respect and deep friendship of biological control associates in every country he visited.

These world-wide explorations over the years led to successful introductions into California of natural enemies of oriental fruit fly, black scales, spotted alfalfa aphid, walnut aphid, Egyptian alfalfa weevil, and of various pests of ornamental plantings.

The detailed and scholarly work which van den Bosch carried out in these applied biological control programs contributed much basic knowledge to entomological and ecological science. His early work in Hawaii, with collaborators, on various parasites introduced to control the oriental fruit fly, included the discovery, characterisation and exploitation of a previously unknown egg-larval parasite. These Hawaiian studies provided important information on the nature of parasite competition, succession, and the theory of, and evaluation of effects of, multiple parasitism.

Another major biological control contribution concerned the spotted alfalfa aphid in California. While development of a variety of alfalfa resistant to this pest came later, the prior introduction of parasites of the aphid had a major role in the early management of this serious pest, and it still has a significant role. Van den Bosch was the key figure in these introductions-discovering and importing from the Middle East and Mediterranean areas the parasites which were ultimately responsible for success. $\mathrm{He}$ carefully followed the progress of the pest aphid and its natural enemy populations in the field for several years. One of his findings was that there may be a certain critical inoculation density necessary when colonising a new parasite in order to obtain successful establishment. He also obtained fundamental data relating to the success of a parasite in one climatic area but its failure in another which helps to clarify our knowledge of the patchiness of biological control successes and failures.
Foreign exploration for parasitic and predatory insects is not an easy task and, commonly, the results cannot be assessed for some years. In 1960 Professor van den Bosch collected a parasite of the walnut aphid in France and shipped it to California where it was released in Persian walnut growing areas of the state. It became established and effective, however, only in the coastal areas of southern California. In 1968 Van searched in Iran, a region climatically more similar to that of the interior and middle regions of California, for a parasite that might be better adapted. Though he found in Iran the same taxonomist's species that he had collected in France he suspected that the Iranian stock represented a different and potentially more valuable biotype. The Iranian biotype was then colonised widely in northern California, became established immediately, and by 1970 had effectively controlled the aphid.

The successful biological control of the spotted alfalfa aphid and the walnut aphid reduced crop losses and treatment costs thus saving millions of dollars to Californian agriculture.

Concurrent with and inherent in much of this 'exploration and establishment' research, Professor van den Bosch studied a number of both basic and applied problems-for example, ones relating to host specificity, timing or phenology, trophic relationships, and impact of a number of parasites on their hosts, e.g. on alfalfa weevils and several pest aphids on alfalfa, walnuts and ornamental plants. He also studied the role of hyperparasites which attack beneficial primary parasites. He made fundamental studies on the haemocytic encapsulation of weevil parasites and related this to biological control success or failure.

While Professor van den Bosch's activities as an energetic, vocal and successful researcher in biological control are widely known, his contributions to the development and theory of modern integrated pest management (=integrated control) are sometimes overlooked. In 1959 he joined with Ray F. Smith, Vernon M. Stern and K. S. Hagen to explicitly formulate the notion of the 'economic threshold' of pest impact and put forward forcefully the idea of integrating chemical, cultural and biological control tactics in a broad strategy of pest containment, rather than that of preventative or exterminative management by use of pesticides. This approach has now been developed further and is currently being fostered at the highest levels of government and 'implemented' increasingly in many parts of the world with, of course, varying degrees of sophistication and success.

Alfalfa and cotton in California became van den Bosch's focal points for developing his concepts and applications of integrated control. $\mathrm{He}$ was among those many in California and elsewhere who contributed greatly to demonstrate not only the tremendous adverse impact on natural enemies but on the ecosystem otherwise, of pesticides when used in an arbitrary unilateral manner. In so doing, these researchers have brought to the surface the enormous amount of naturallyoccurring biological control that passes unnoticed until it has been 'upset' by use of pesticides. Professor van den Bosch illustrated, along with these others, how this naturally-occurring biological control can be conserved and augmented.

Van saw the world from the dual perspective of a scientist and an alarmed layman and environmentalist. Early on, he became acutely aware of the awesome problems arising from indiscriminate use of potent, synthetic, broad-spectrum, long-lasting biocides in our agricultural ecosystems. This was unacceptable to him as a scientist. It threatened the discipline to which he was devoted, and it represented an assault upon invaluable resources, the biological control agents, without which the insect pests would become truly agents of disaster. It was also an assault upon our basic supporting environment itself. In recent years a major part of his energies were devoted to speaking, writing and advocating that this problem be recognised and that the necessary research, education and implementation undertaken to correct it.

Perhaps more than anyone else in the world, Professor van den Bosch, an inspiring teacher and scientist, was successful in conveying to students all over the world and to the various elements of society in general an awareness that pesticides are not simply an unmitigated blessing - that, quite the contrary, as they have been used they can be as much a threat to agricultural production as they are to human wellbeing and environmental integrity. This is perhaps his greatest single achievement and for which he will be remembered.

This deep concern of Professor van den Bosh's for our environment and his contempt for those who defile it were expressed in his inimitable and provocative style in his various writings and last book, The Pesticide Conspiracy. This book should be read by all concerned citizens of the world.

Lastly, Van loved life. His was a bright spirit and a fighting heart; perhaps it is this that his friends and colleagues shall miss the most.

Carl Huffaker Nettie Mackey and other friends 